\title{
Gene Identification for the cblD Defect of Vitamin $\mathrm{B}_{12}$ Metabolism
}

\author{
David Coelho, Ph.D., Terttu Suormala, Ph.D., Martin Stucki, M.Sc., \\ Jordan P. Lerner-Ellis, Ph.D., David S. Rosenblatt, M.D., \\ Robert F. Newbold, Ph.D., Matthias R. Baumgartner, M.D., \\ and Brian Fowler, Ph.D.
}

From the Metabolic Unit, University Children's Hospital, Basel (D.C., T.S., J.P.L.-E., B.F.), and the Division of Metabolism and Molecular Pediatrics, University Children's Hospital (M.S., M.R.B.), and Zurich Center for Integrative Human Physiology, University of Zurich, Zurich (M.S.) - both in Switzerland; Department of Human Genetics, McGill University, and Division of Medical Genetics, McGill University Health Centre - both in Montreal (J.P.L.-E., D.S.R.); and Brunel Institute of Cancer Genetics and Pharmacogenomics, Brunel University, Uxbridge, United Kingdom (R.F.N.). Address reprint requests to Dr. Fowler at the Metabolic Unit, University Children's Hospital Basel, Roemergasse 8, CH-4005 Basel, Switzerland, or at brian.fowler@ukbb.ch.

Drs. Coelho and Suormala contributed equally to this article, as did Drs. Baumgartner and Fowler.

N EngIJ Med 2008;358:1454-64.

Copyright $(2008$ Massachusetts Medical Society.

\section{A BSTRACT}

\section{BACKGROUND}

Vitamin $B_{12}$ (cobalamin) is an essential cofactor in several metabolic pathways. Intracellular conversion of cobalamin to its two coenzymes, adenosylcobalamin in mitochondria and methylcobalamin in the cytoplasm, is necessary for the homeostasis of methylmalonic acid and homocysteine. Nine defects of intracellular cobalamin metabolism have been defined by means of somatic complementation analysis. One of these defects, the cblD defect, can cause isolated methylmalonic aciduria, isolated homocystinuria, or both. Affected persons present with multisystem clinical abnormalities, including developmental, hematologic, neurologic, and metabolic findings. The gene responsible for the cblD defect has not been identified.

\section{METHODS}

We studied seven patients with the cblD defect, and skin fibroblasts from each were investigated in cell culture. Microcell-mediated chromosome transfer and refined genetic mapping were used to localize the responsible gene. This gene was transfected into cblD fibroblasts to test for the rescue of adenosylcobalamin and methylcobalamin synthesis.

\section{RESULTS}

The cblD gene was localized to human chromosome 2q23.2, and a candidate gene, designated MMADHC (methylmalonic aciduria, cblD type, and homocystinuria), was identified in this region. Transfection of wild-type MMADHC rescued the cellular phenotype, and the functional importance of mutant alleles was shown by means of transfection with mutant constructs. The predicted MMADHC protein has sequence homology with a bacterial ATP-binding cassette transporter and contains a putative cobalamin binding motif and a putative mitochondrial targeting sequence.

\section{CONCLUSIONS}

Mutations in a gene we designated MMADHC are responsible for the cblD defect in vitamin $\mathrm{B}_{12}$ metabolism. Various mutations are associated with each of the three biochemical phenotypes of the disorder. 
V ITAMIN B $B_{12}$ (COBALAMIN) IS ESSENTIAL for normal development and survival in humans and must be obtained from animal products or supplements. Inside the cell, it is converted to two active cofactors, adenosylcobalamin and methylcobalamin (Fig. 1). ${ }^{1}$ Adenosylcobalamin is the coenzyme for mitochondrial methylmalonyl-coenzyme A mutase, which converts L-methylmalonyl-coenzyme A to succinyl-coenzyme A and is involved in catabolism of odd-chain fatty acids and some amino acids. Methylcobalamin is the coenzyme for cytosolic methionine synthase, which converts homocysteine to methionine and is essential for normal one-carbon metabolism, which is in turn involved in vital cellular processes such as methylation and DNA synthesis. ${ }^{1}$ Disturbances of cobalamin-cofactor synthesis due to acquired or inherited alterations result in elevated levels of homocysteine and methylmalonic acid, which are associated with multisystem clinical abnormalities similar to those seen in patients with severe nutritional vitamin $\mathrm{B}_{12}$ deficiency, including lethargy, hypotonia, developmental delay, seizures, and megaloblastic anemia.

Inborn errors of cobalamin-cofactor synthesis represent a heterogeneous and important group of rare disorders. Intracellular cobalamin metabolism involves multiple steps between the lysosomal release of cobalamin and the synthesis of adenosylcobalamin in the mitochondria and methylcobalamin in the cytosol. To date, nine distinct defects of this pathway have been defined in vitro with the use of somatic complementation analysis. The complementation groups thus identified have been designated cblA, cblB, cblC, cblD, cblE, cblF, cblG, cblH, and mut (Fig. 1). ${ }^{2,3}$ The responsible genes are known except for cblD, cblF, and $\mathrm{cblH}$, although the function of some of the associated proteins is not clear. The cblC and cblF disorders cause combined homocystinuria and methylmalonic aciduria; cblA, cblB, cblH, and mut cause isolated methylmalonic aciduria; and cblE and cblG cause isolated homocystinuria. The cblD defect (Online Mendelian Inheritance in Man number, 277410) ${ }^{2}$ is puzzling in that some patients have combined methylmalonic aciduria and homocystinuria (called "cblD original" by Suormala et al. ${ }^{2}$ but herein called "cblD-combined"), some have only isolated homocystinuria (called "cblDvariant 1"2 or, herein, "cblD-homocystinuria"), and others have only methylmalonic aciduria ("cblDvariant 2"2 or, herein, "cblD-methylmalonic acid- uria"). Here, we describe our identification of the cblD gene, confirmation of its identity by using biochemical and molecular studies, and demonstration of functionally significant mutations in patients with the cblD defect.

METHODS

\section{PATIENTS AND CELL LINES}

The study was performed between 2004 and 2007. Seven unrelated patients with the cblD defect were studied. Written informed consent was obtained from the parents of each patient, and patients who could give assent did so. The study was approved by the local ethics committee.

Cultures of skin fibroblasts were obtained for diagnostic purposes, and referring physicians approved the use of the samples for our investigation of the origin of the disease. We immortalized fibroblasts using the plasmid pRNS1 ${ }^{4}$ and electroporation (Gene Pulser II, BioRad). Immortalization did not markedly affect cellular function (data not shown).

The functional integrity of the methylmalonicacid pathway was evaluated by measuring the degree of incorporation of $\left[{ }^{14} \mathrm{C}\right]$ propionate into macromolecules and formation of adenosylcobalamin from $\left[{ }^{57} \mathrm{Co}\right]$ cyanocobalamin, as described previously. ${ }^{2}$ The integrity of methionine synthase in the homocysteine pathway was defined as the formation of methionine from $\left[{ }^{14} \mathrm{C}\right]$ formate and synthesis of methylcobalamin from $\left[{ }^{57} \mathrm{Co}\right]$ cyanocobalamin. ${ }^{2}$

Somatic complementation analysis ${ }^{2}$ confirmed that all fibroblast cell lines from patients belonged to the cblD group (including one that had been used to define $\mathrm{cblD}^{5}$ ). A fibroblast cell line from one of the seven patients had previously been assigned to a new complement group (cblH) by Watkins et al., ${ }^{6}$ but we show here that it in fact belongs to the cblD complement group (Fig. 1 in the Supplementary Appendix, available with the full text of this article at www.nejm.org).

\section{MICROCELL-MEDIATED CHROMOSOME TRANSFER}

Mouse-human monochromosomal hybrid cell lines (donor cells), each carrying a single human chromosome tagged with a hygromycin resistance gene, ${ }^{7}$ were used to serially transfect one of the immortalized cblD-homocystinuria cell lines (recipient cells) with the use of microcell-mediated chromosome transfer, as described previously ${ }^{8}$ 


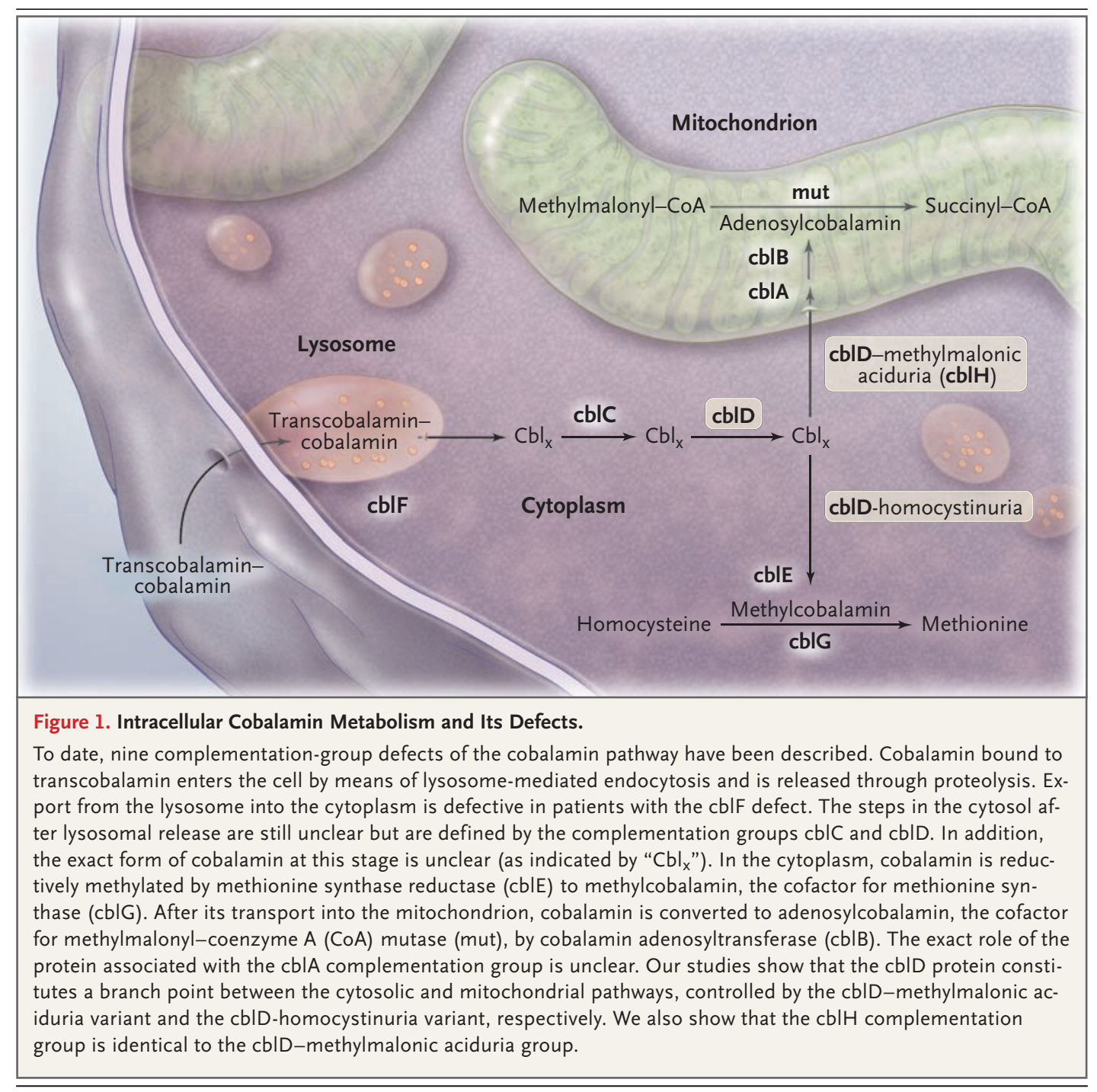

(also see Table 1 in the Supplementary Appendix). Cells containing each transfected human chromosome were selected on the basis of growth in medium containing hygromycin. Colonies were subcultured and assayed for methylcobalamin synthesis. Those that showed such synthesis, and thus the rescue of cellular function, were defined as positive colonies; those that did not were defined as negative colonies.

\section{GENE MAPPING}

Positive colonies were tested for contamination by mouse DNA with the use of the mouse-specific microsatellite markers BAM5 and RSINE1 SINE/B4. ${ }^{9,10}$ Positive colonies that were free of mouse DNA contamination and negative colonies then were used in the fine mapping of the donor chromosome, by means of microsatellite markers, to define the chromosomal segment containing the putative gene corresponding to the cblD defect. The presence of these microsatellite markers was tested with the use of the polymerase-chain-reaction (PCR) assay, involving fluorescently labeled primers. Products were visualized in an automated sequencer (ABI Prism 3100, Applied Biosystems) and analyzed with Genotyper software (version 2.5, Applied Biosystems). The chromosomal region defined by the microsatellite markers was examined for candidate genes, and a suitable candidate was selected on the basis of sequence characteristics.

\section{DNA SEQUENCING AND MUTATION ANALYSIS}

Total RNA was extracted from cultured fibroblasts with the use of the RNeasy Kit (Qiagen), and 
full-length complementary DNA (cDNA) for the candidate gene was amplified by means of a reverse-transcriptase PCR (RT-PCR) assay involving specific primers and was sequenced according to the ABI BigDye method (Applied Biosystems). To confirm mutations identified in the RT-PCR products, the corresponding exons were amplified through the PCR assay from genomic DNA, with the use of flanking intronic primers, and were sequenced.

\section{EXPRESSION OF CANDIDATE GENE CDNA IN FIBROBLASTS}

Constructs containing wild-type and mutant cDNA sequences for the candidate gene were prepared in pTracer-CMV2 or pcDNA3.2/V5 expression vectors (Invitrogen), as described previously. ${ }^{11}$ Constructs were transfected into immortalized fibroblasts by means of electroporation. Transfection efficiency was 5 to $22 \%$, as determined by estimating the proportion of cells coexpressing the green fluorescent protein from the pTracer construct. Rescue of cellular function was tested by measuring methionine and methylcobalamin synthesis or adenosylcobalamin synthesis.

\section{STATISTICAL ANALYSIS}

We tested the statistical significance of the data on rescue of function by using the unpaired t-test (twotailed), with Welch's correction for unequal variances, and GraphPad Prism software (version 4). $P$ values less than 0.05 were considered to indicate statistical significance.

\section{RESULTS}

\section{CLINICAL DATA}

The clinical features of the seven patients are shown in Table 1. Two patients had the isolated homocystinuria phenotype, and two had the isolated methylmalonic aciduria phenotype. These four patients have been described previously (Table 1). The three other patients, two of whom are newly described in this study, had the combined phenotype (methylmalonic aciduria and homocystinuria).

\section{GENE LOCALIZATION}

To identify the chromosome containing the cblD gene, we transfected immortalized cblD-homocystinuria cells (from Patient 2) with individual human chromosomes contained in mouse-human singlechromosome hybrid cell lines using microcell- mediated chromosome transfer. We then tested the resulting cell lines for rescue of function by measuring methylcobalamin synthesis. Transfection with chromosome 2 yielded 48 colonies that showed correction of methylcobalamin synthesis (positive colonies) and 24 colonies that did not (negative colonies) (Table 1 in the Supplementary Appendix). The positive colonies were screened for mouse-specific sequences, and four were found to be free of contamination with mouse DNA.

A panel of 38 microsatellite markers spanning chromosome 2 was used to perform fine mapping of the chromosome fragments from the 4 positive colonies and 22 of the negative colonies (see Table 2 in the Supplementary Appendix). This finemapping procedure identified a 10.2-Mb DNA segment between markers D2S150 and D2S2324 that was present in DNA from positive colonies but absent in all the negative colonies (Fig. 2 in the Supplementary Appendix). This mapped the cblD gene to the chromosome region 2q22.1-2q23.3 (Fig. 2A), which contains 28 genes (according to the deCODE genetic map; for details, see the accession numbers and URLs in Note 1 in the Supplementary Appendix). The C2orf 25 gene was selected as a candidate because of its homology ${ }^{14}$ to a putative mitochondrial ATPase component of a bacterial ATP-binding cassette (ABC) transporter (YP_218380) and because cobalamin transport in bacteria is facilitated by an $A B C$ transport system. ${ }^{15}$

\section{MUTATION ANALYSIS}

The full-length cDNA for the candidate gene C2orf25 was amplified by means of RT-PCR and specific primers (Table 3 in the Supplementary Appendix). The C2orf 25 gene was then sequenced from cDNA from each of the seven patients with the cblD defect, and mutations for each patient were identified. These mutations were further confirmed with the use of PCR amplification of the appropriate exons from genomic DNA, involving flanking intronic primers (Table 3 in the Supplementary Appendix). We identified nine mutations, with two mutant alleles in each patient (Table 1 and Fig. 2B).

Five of the mutations we identified are predicted to lead to a premature stop codon, resulting in a truncated protein: two nonsense mutations $(160 \mathrm{C} \rightarrow \mathrm{T}, 748 \mathrm{C} \rightarrow \mathrm{T})$, two deletions (57_64del, $696+1$ 4del), and one duplication (419dupA). The $696+1$ 4del splice-site mutation was shown by 


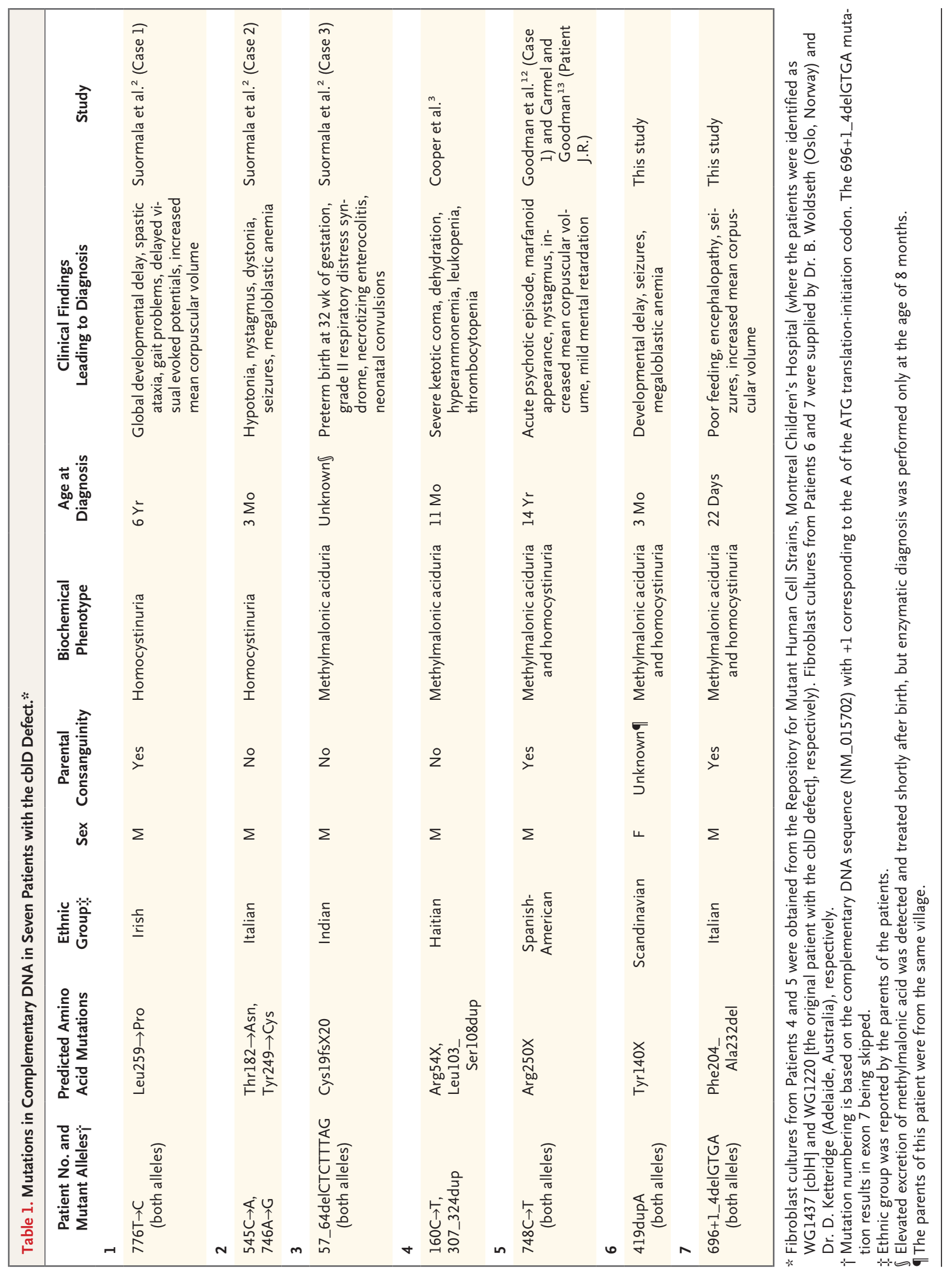




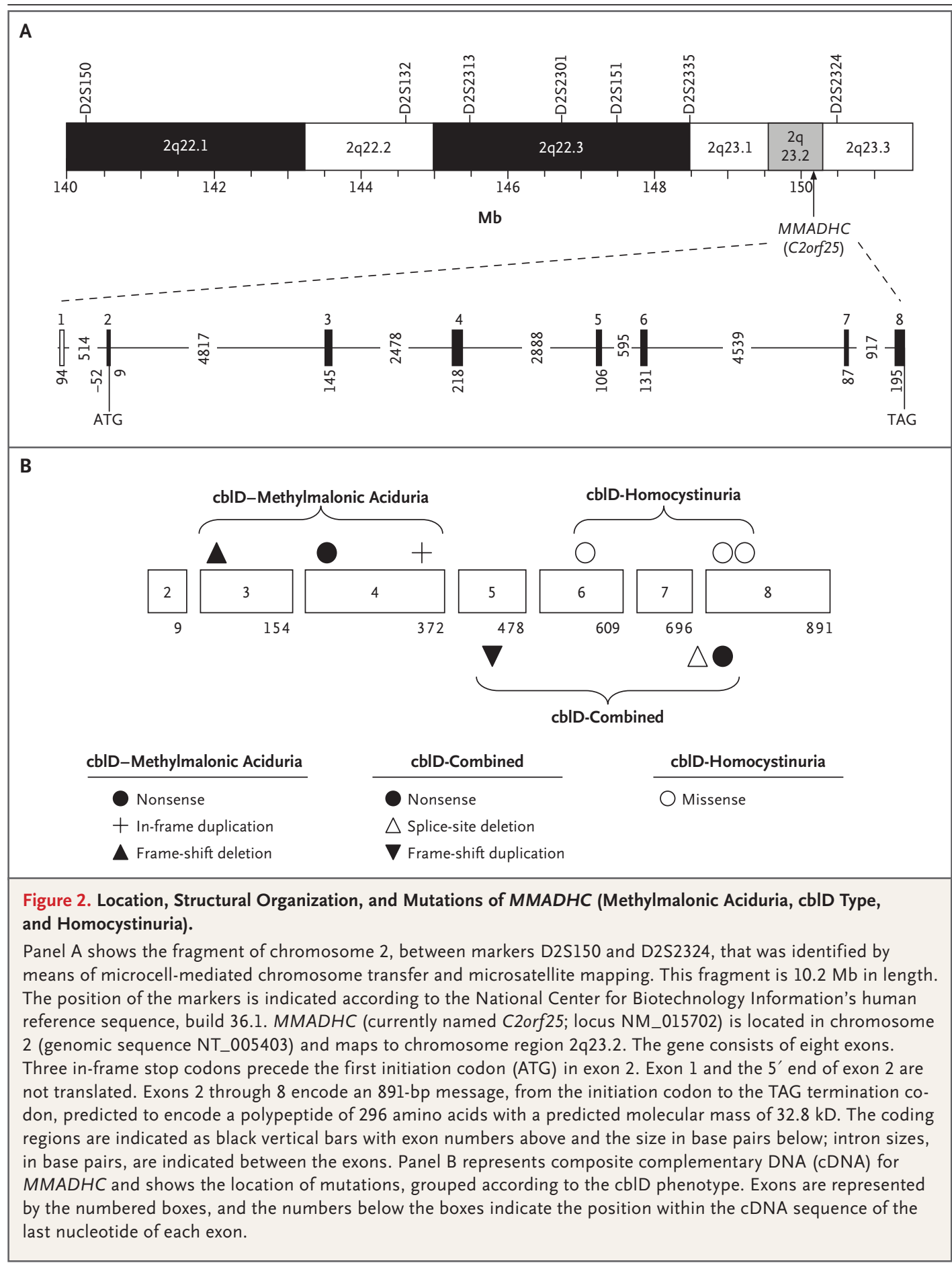

means of RT-PCR to cause the skipping of exon 7. identified. This mutation is predicted to add six This mutation was present in the homozygous state in Patient 7 and was found in the heterozygous state in both parents and in an at-risk fetus in this family (data not shown).

One in-frame duplication (307_324dup) was amino acids to the protein product.

Three mutations causing a single amino acid change were found $(545 \mathrm{C} \rightarrow \mathrm{A}, 746 \mathrm{~A} \rightarrow \mathrm{G}$, and $776 \mathrm{~T} \rightarrow \mathrm{C}$ ), each occurring in a region of the gene that is highly conserved among species (Fig. 3). 


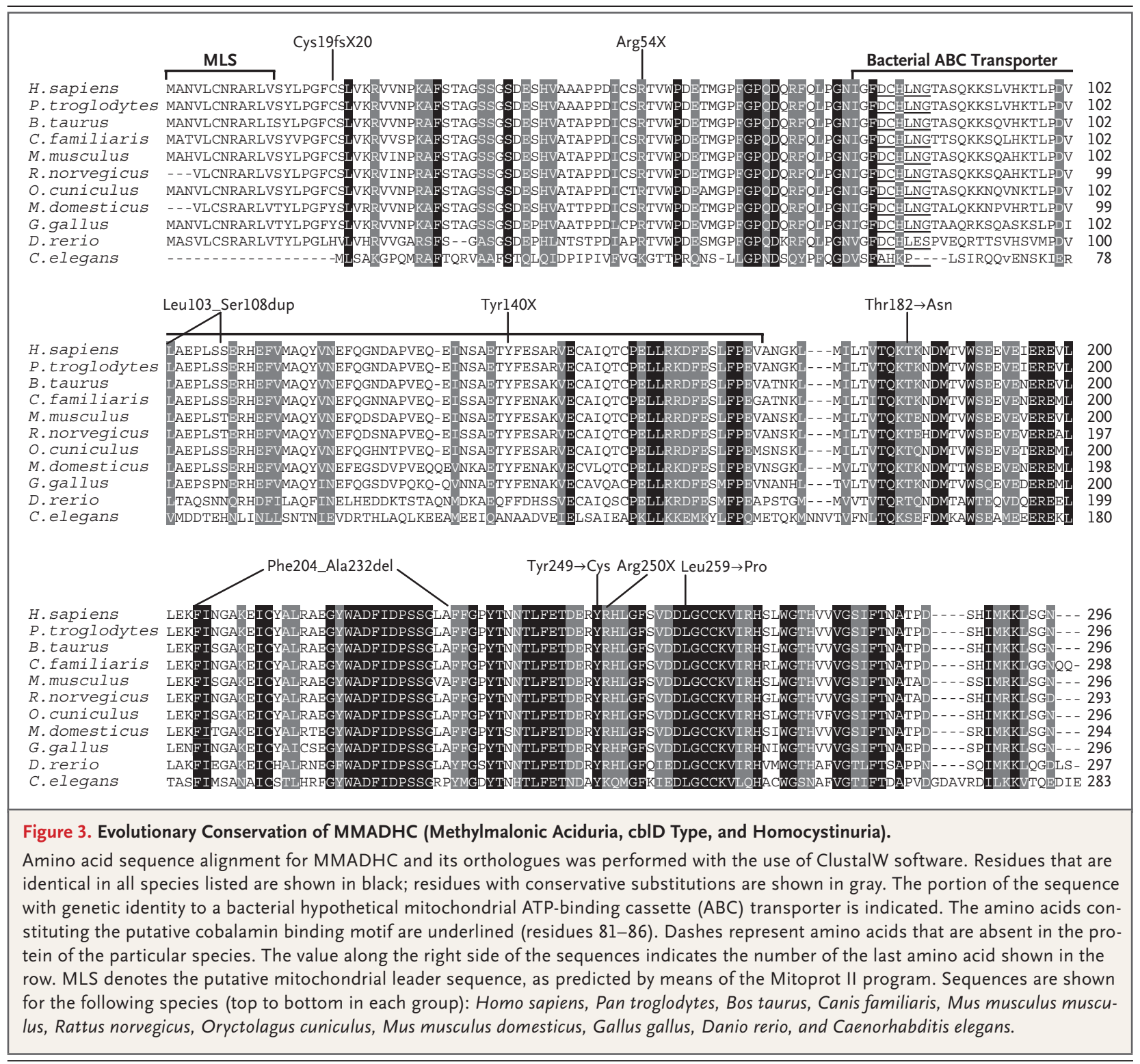

These three missense mutations occurred in patients of European origin and did not occur in 100 control chromosomes from subjects with the same ethnic backgrounds, substantially reducing the likelihood that these are common polymorphisms. Parental DNA, used to rule out a deletion in the homozygous patients, was available from only one family.

\section{TISSUE EXPRESSION AND PROTEIN CHARACTERIZATION}

We searched databases of known expressed sequences of the human genome to ascertain the tis- sue expression of the C2orf25 gene. This gene appears to be expressed at high levels in most tissues (Note 2 in the Supplementary Appendix). To detect possible multiple transcripts, we amplified C2orf 25 from fibroblast messenger RNA (mRNA), by using RT-PCR and various primers. We found only a single cDNA product, with a coding region of $891 \mathrm{bp}$, encoding a putative polypeptide of 296 amino acids and a predicted molecular weight of 32.8 kD (Fig. 3). Residues 1 through 12 constitute a possible mitochondrial leader sequence, which suggests targeting of the expressed protein to mitochondria. ${ }^{16}$ Residues 81 though 86 match the 
vitamin $\mathrm{B}_{12}$ binding motif, Asp-Xaa-His-XaaXaa-Gly, constituting a putative binding site for cobalamin. ${ }^{17}$

\section{EXPRESSION OF HUMAN C20rf25 CDNA IN FIBROBLASTS}

To prove that the C2orf25 gene is responsible for the cblD phenotype, we tested the ability of wildtype and mutant constructs to rescue cellular function (Fig. 4). The wild-type construct rescued methionine synthesis and methylcobalamin synthesis, which were both restored to 52 to $100 \%$ of the control values in both cblD-homocystinuria and cblD-combined fibroblasts with the use of the pTracer vector (Fig. 4A and 4B). Adenosylcobalamin synthesis was not reproducibly corrected with the use of the pTracer wild-type construct. To test for rescue of adenosylcobalamin synthesis, we repeated the experiment with the DNA3.2/V5 vector containing the wild-type construct and showed restoration of adenosylcobalamin synthesis to $68 \%$ of the control value in a cblD-combined cell line (Fig. 4C).

Constructs containing the missense alleles associated with isolated homocystinuria $(545 \mathrm{C} \rightarrow \mathrm{A}$, $746 \mathrm{~A} \rightarrow \mathrm{G}$, and $776 \mathrm{~T} \rightarrow \mathrm{C}$ ) did not restore methionine or methylcobalamin synthesis in either cblD-homocystinuria or cblD-combined cells, confirming that these mutant alleles cause the homocystinuria phenotype (Fig. 4A and 4B). Both constructs containing the mutations found in isolated methylmalonic aciduria (57_64del and $160 \mathrm{C} \rightarrow \mathrm{T}$ ) rescued the synthesis of methylcobalamin (Fig. 4B).

Together, these findings suggest that mutations in the C2orf 25 gene are responsible for the cblD defect. We have therefore designated the gene $M M A D H C$, or methylmalonic aciduria, cblD type, and homocystinuria (to indicate either the isolated phenotype or the combined phenotype).

\section{DISCUSSION}

We show evidence that mutations of the gene C2orf25, which we have designated MMADHC, cause the cblD defect in vitamin $B_{12}$ metabolism. Our evidence includes the identification of nonconservative mutations in MMADHC in each of seven patients with cblD defects and the demonstration that expression vectors containing the wild-type $M M A D H C$ gene rescue cblD function in fibroblast cell lines. The predicted MMADHC protein contains the putative cobalamin binding motif and a putative mitochondrial targeting sequence.
A complete analysis of the cblD defect requires an explanation of how mutations in the candidate gene lead to three distinct biochemical phenotypes. Although our data as described do not fully satisfy this requirement, our results suggest that the nature and location of the mutations are correlated with the biochemical phenotype, as illustrated in Figure 2B. Mutations found in the patients with cblD-methylmalonic aciduria are located toward the $\mathrm{N}$-terminal part of the protein and consist of a nonsense mutation, a duplication, and a frame-shift deletion. Mutations found in the patients with cblD-homocystinuria are located toward the C-terminal part of the protein and consist of three missense mutations. Mutations found in the patients with the cblD-combined phenotype are located toward the C-terminal part of the protein and consist of a nonsense mutation, a splice-site deletion, and a frame-shift duplication.

Explaining these associations fully will require further studies. However, we offer the following speculations. The two patients with the cblDmethylmalonic aciduria defect carry mutations that are predicted to lead to truncated proteins of 19 amino acids in length (57_64del) or 53 amino acids in length $(160 \mathrm{C} \rightarrow \mathrm{T})$. We propose that the Met62 codon acts as a second start codon and leads to the reinitiation of translation, ${ }^{18}$ resulting in the formation of a shorter functional cblD protein product that lacks the putative mitochondrial leader sequence but allows for normal methylcobalamin synthesis. This would explain the isolated methylmalonic aciduria without homocystinuria in Patients 3 and 4 and is in accordance with the rescue of methionine and methylcobalamin synthesis in cblD-homocystinuria and cblDcombined cell lines transfected with the mutant alleles 57_64del and 160C $\rightarrow \mathrm{T}$. In support of this "reinitiation of translation" hypothesis, a strong Kozak consensus sequence ${ }^{19}$ occurs at cDNA positions $184-3$ and $184+4$ (A at position -3 and G at position +4) in the MMADHC gene.

Both patients with isolated homocystinuria carry missense mutations $(545 \mathrm{C} \rightarrow \mathrm{A}, 746 \mathrm{~A} \rightarrow \mathrm{G}$, and 776T $\rightarrow$ C) that are sufficient to cause deficient synthesis of methylcobalamin. However, we speculate that these mutations allow for the formation of a modified protein with an intact functional domain for the synthesis of adenosylcobalamin.

The patients with combined homocystinuria and methylmalonic aciduria carry mutations (419dupA, 696+1_4del, and 748C $\rightarrow \mathrm{T}$ ) that are pre- 
dicted to lead to premature stop codons. We presume that these mutations would result either in a defective protein lacking both functional domains or in a low, steady-state abundance of MMADHC mRNA by the mechanism of nonsensemediated mRNA decay.

These interpretations imply that at least two functional domains are present in the cblD protein and that the nature and location of the mutations correlate with the biochemical phenotype. However, this hypothesis remains speculative until proved in more patients. An alternative hypothesis is that even under normal conditions, two proteins are produced. However, we find no evidence of two different transcripts, and a single transcript of MMADHC rescues both biochemical phenotypes. This gene can be added to the list of genes known to be associated with multiple phenotypes involving various subcellular compartments, such as the amnionless gene ${ }^{20}$ and the multiple sulfatase gene. ${ }^{21}$ To our knowledge, $M M A D H C$ is unique in that the three distinct biochemical phenotypes involve both the cytosolic and mitochondrial pathways.

The protein sequence of MMADHC is highly conserved among various mammalian species (Fig. 3). MMADHC is not a member of any previously identified gene family but was initially selected because of homology to a putative bacterial $\mathrm{ABC}$ transporter.

Although the segment of 91 amino acids between residues 78 and 168 shares $28 \%$ identity and $46 \%$ similarity with a putative ATPase component of an $\mathrm{ABC}$ transporter from Salmonella enterica (YP_218380), the cblD protein lacks critical motifs of $\mathrm{ABC}$ transporters such as Walker A, Walker B, and an $\mathrm{ABC}$ signature. ${ }^{22}$ This makes it unlikely that the cblD protein is a classic $\mathrm{ABC}$ transporter. $\mathrm{ABC}$ transporters are a diverse family of proteins with multiple functions; MMADHC may be a new type of $A B C$ transporter or may be involved in a complex that facilitates transport in a fashion similar to that of $\mathrm{ABC}$ transporters.

It is not known how cobalamin enters the mitochondria in humans. Both active diffusion and passive diffusion have been suggested. ${ }^{23,24}$ In some bacteria, cobalamin transport is facilitated by two processes. First, it is transported through the outer membrane by the BtuB transporter, ${ }^{15}$ which is mediated by Ton $\mathrm{B},{ }^{25}$ a protein that couples energy from the proton motive force to the transport of cobalamin. Second, it is transported
Figure 4 (facing page). Expression of Wild-Type and Mutant Alleles of Human MMADHC (Methylmalonic Aciduria, cbID Type, and Homocystinuria) in Immortalized cbID-Combined, cblD-Homocystinuria, and Control Fibroblasts.

Cells from Patient 7 with the cblD-combined phenotype (homozygous for 696+1_4delGTGA), Patient 2 with the cblD-homocystinuria phenotype (cblD-HC) (compound heterozygous for missense mutations $545 \mathrm{C} \rightarrow \mathrm{A}$ and $746 \mathrm{~A} \rightarrow \mathrm{G}$ ), and one control were immortalized and used for transfection experiments. Transient transfection was performed by means of electroporation with pTracer ( $\mathrm{pTr}$ ) vectors containing an MMADHC allele: the wild-type allele, one of the three missense alleles $(545 \mathrm{C} \rightarrow \mathrm{A}, 746 \mathrm{~A} \rightarrow \mathrm{G}$, or $776 \mathrm{~T} \rightarrow \mathrm{C}$ ) associated with cblD-HC, or the frame-shift deletion 57_64delCTCTTTAG or the nonsense mutation $160 \mathrm{C} \rightarrow \mathrm{T}$ associated with cblD-methylmalonic aciduria. Background activity was measured in cells transfected with empty pTracer vector (pTr only). Panel A shows the formation of methionine from $\left[{ }^{14} \mathrm{C}\right]$ formate, and Panels $B$ and $C$ show the synthesis of methylcobalamin, and adenosylcobalamin,

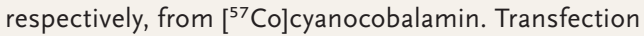
of the cblD-combined cell line and the control cell line was also performed with the pcDNA3.2/V5 vector containing wild-type MMADHC. Background activity was measured in cells transfected with empty pcDNA3 vector (pcDNA3.2 only). The data are means, and the I bars indicate the range of results of single determinations from each experiment. For Panels $A$ and $B$, the values are from three replicate experiments, and $P$ values are shown only for comparisons indicating rescue of function. For Panel C, values for the pTracer vector are from seven replicate experiments, and those for the pcDNA3.2 vector are from three replicate experiments.

through the inner membrane by the BtuFCD ABC transport system..$^{22}$ The C-terminal region of the human cblC protein (MMACHC) folds in a manner similar to that of TonB from Escherichia coli, ${ }^{26}$ and the human cblD protein MMADHC, the existence of which we have predicted, shares some sequence identity with an $\mathrm{ABC}$ transporter from S. enterica. It is tempting to speculate that the $M M A C H C$ and MMADHC genes may have evolved to carry out functional roles that are similar to those of their bacterial counterparts, by forming structurally similar proteins.

In conclusion, we studied seven patients with the cblD defect in vitamin $\mathrm{B}_{12}$ metabolism. We found that mutations in a gene we designated $M M A D H C$ are responsible for this defect, and we demonstrated that various mutations are associated with each of the three biochemical phenotypes of the disorder. 


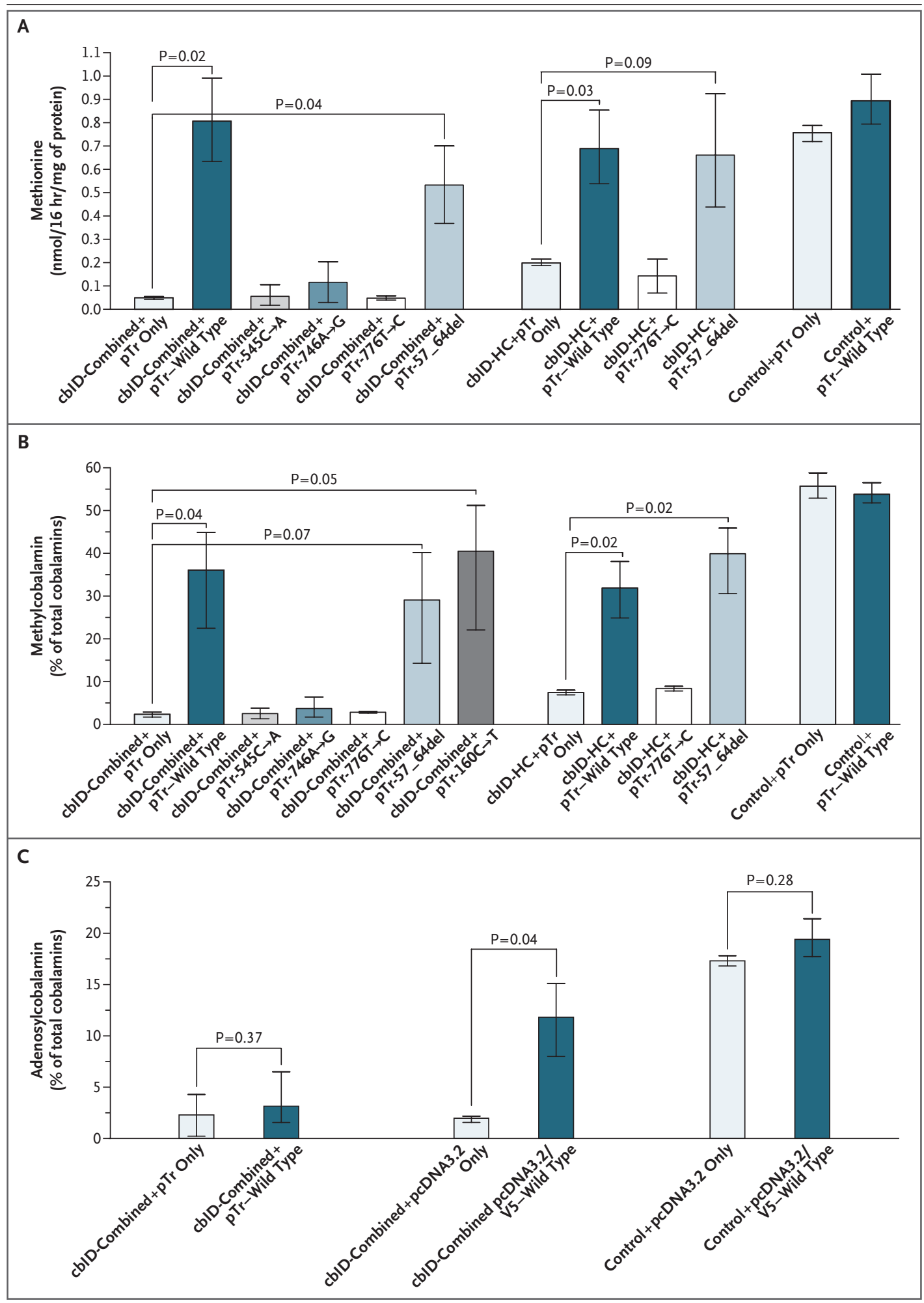


Supported by grants from the Swiss National Foundation (3200-066878/1,320000-109635/1, and 3200AO-109219/1), the Canadian Institutes of Health Research (CIHR), and the Hess B. Finestone Laboratory. Dr. Lerner-Ellis is the recipient of a Canadian Graduate Scholarship doctoral award from the CIHR.

No potential conflict of interest relevant to this article was reported.
We thank the clinicians who provided the samples from patients and clinical information, David Watkins for the parallelcomplementation analysis in the cblH cell line, and Martina Plasilova, Beat Steinmann, and Patricie Paesold for useful discussions. The pRNS1 immortalized control fibroblast cell line was a gift from Prof. Viktor Kozich and Dr. Petra Zavadakova (Prague, Czech Republic).
REFERENCES

1. Rosenblatt D, Fenton WA. Inherited disorders of folate and cobalamin transport and metabolism. In: Scriver CR, Beaudet AL, Sly WS, Valle D, eds. The metabolic and molecular bases of inherited disease. 8th ed. New York: McGraw-Hill, 2001:3897-933.

2. Suormala T, Baumgartner MR, Coelho $\mathrm{D}$, et al. The cblD defect causes either isolated or combined deficiency of methylcobalamin and adenosylcobalamin synthesis. J Biol Chem 2004;279:42742-9.

3. Cooper BA, Rosenblatt DS, Watkins

D. Methylmalonic aciduria due to a new defect in adenosylcobalamin accumulation by cells. Am J Hematol 1990;34:11520.

4. Litzkas P, Jha KK, Ozer HL. Efficient transfer of cloned DNA into human diploid cells: protoplast fusion in suspension. Mol Cell Biol 1984;4:2549-52.

5. Willard HF, Mellman IS, Rosenberg LE. Genetic complementation among inherited deficiencies of methylmalonylCoA mutase activity: evidence for a new class of human cobalamin mutant. Am J Hum Genet 1978;30:1-13.

6. Watkins D, Matiaszuk N, Rosenblatt DS. Complementation studies in the cblA class of inborn error of cobalamin metabolism: evidence for interallelic complementation and for a new complementation class (cblH). J Med Genet 2000;37: 510-3.

7. Cuthbert AP, Trott DA, Ekong RM, et al. Construction and characterization of a highly stable human:rodent monochromosomal hybrid panel for genetic complementation and genome mapping studies. Cytogenet Cell Genet 1995;71: 68-76.

8. Hunt JD. Evaluation of phenotypic al- terations by microcell-mediated chromosome transfer. Anal Biochem 1996;238: 107-16.

9. Gebhard W, Zachau HG. Organization of the R family and other interspersed repetitive DNA sequences in the mouse genome. J Mol Biol 1983;170:255-70.

10. Walker JA, Hugues DA, Hedges DJ, et al. Quantitative PCR for DNA identification based on genome-specific interspersed repetitive elements. Genomics 2004;83 518-27.

11. Baumgartner MR, Almashanu S, Suormala $\mathrm{T}$, et al. The molecular basis of human 3-methylcrotonyl-CoA carboxylase deficiency. J Clin Invest 2001;107:495-504. 12. Goodman SI, Moe PG, Hammond KB Mudd SH, Uhlendorf W. Homocystinuria and methylmalonic aciduria: two cases in a sibship. Biochem Med 1970;4:500-15.

13. Carmel R, Goodman SI. Abnorma deoxyuridine supression test in congenital methylmalonic aciduria-homocystinuria without megaloblastic anemia: divergent biochemical and morphological bone marrow manifestations of disordered cobalamin metabolism in man Blood 1982;59:306-11.

14. Gish W, States DJ. Identification of protein coding regions by database similarity search. Nat Genet 1993;3:266-72.

15. Locher KP, Tee AT, Rees DC. The E.coli BtuCD structure: a framework for $\mathrm{ABC}$ transporter architecture and mechanism. Science 2002;296:1091-8.

16. Claros MG, Vincens P. Computationa method to predict mitochondrially imported proteins and their targeting sequences. Eur J Biochem 1996;241:779-86. 17. Drennan CL, Huang S, Drummond JT, Matthews RG, Ludwig ML. How a protein binds $B_{12}$ : a $3.0 \mathrm{~A}$ X-ray structure of $\mathrm{B}_{12}$ binding domains of methionine synthase. Science 1994;266:1669-74.

18. Zhang J, Maquat LE. Evidence that translation reinitiation abrogates nonsense-mediated mRNA decay in mammalian cells. EMBO J 1997;16:826-33.

19. Kozak M. Point mutations define a sequence flanking the AUG initiator codon that modulates translation by eukaryotic ribosomes. Cell 1986;44:283-92.

20. Tanner SM, Aminoff M, Wright FA, et al. Amnionless, essential for mouse gastrulation, is mutated in recessive hereditary megaloblastic anemia. Nat Genet 2003;33:426-9.

21. Cosma MP, Pepe S, Parenti G, et al. Molecular and functional analysis of SUMF1 mutations in multiple sulfatase deficiency. Hum Mutat 2004;23:576-81.

22. Davidson AL. Structural biology: not just another ABC transporter. Science 2002; 296:1038-40.

23. Mahoney MJ, Hart AC, Steen VD, Rosenberg LE. Methylmalonicacidemia: biochemical heterogeneity in defects of 5 deoxyadenosylcobalamin synthesis. Proc Natl Acad Sci U S A 1975;72:2799-803.

24. Fenton WA, Rosenberg LE. Mitochondrial metabolism of hydroxocobalamin: synthesis of adenosylcobalamin by intact rat liver mitochondria. Arch Biochem Biophys 1978;189:441-7.

25. Shultis DD, Purdy MD, Banchs CN, Wiener MC. Outer membrane active transport: structure of the BtuB:TonB complex. Science 2006;312:1396-9.

26. Lerner-Ellis JP, Tirone JC, Pawelek PD, et al. Identification of the gene responsible for methylmalonic aciduria and homocystinuria, cblC type. Nat Genet 2006;38:93100. [Erratum, Nat Genet 2006;38:957.]

Copyright (C) 2008 Massachusetts Medical Society. 